\title{
Benefits of Optional Research Papers: Writing to Learn in an Undergraduate Civil Engineering Course
}

\author{
Sherif Yehia ${ }^{1}$, Cindy Gunn ${ }^{2}$ \\ Department of Civil Engineering, College of Engineering, American University of Sharjah ${ }^{1}$ \\ Office of Undergraduate Affairs and Instruction, American University of Sharjah ${ }^{2}$ \\ United Arab Emirates
}

\begin{abstract}
This paper investigates civil engineering students' perceptions of the usefulness of their participation in an optional course-related research paper. The first set of data was collected immediately after the students completed the project. The second set was collected several years after the participating students had graduated. Results from the first set of data indicate that the students felt they benefited from the optional research project by learning valuable research skills and gaining a more thorough understanding of the topic. Results from the second set support this and further indicate that the students' involvement in the project had a lasting impact on the students' academic and career performance. Implications from this study include a call for the inclusion of more research projects, in engineering courses at all levels. Suggested activities for professors who wish to incorporate writing to learn in their curriculum are offered.
\end{abstract}

\section{Introduction}

American University of Sharjah (AUS) is located in the Emirate of Sharjah in the United Arab Emirates. AUS is a multi-cultural co-educational private university following an American curriculum with approximately 6,000 undergraduate and graduate students from more than 95 nationalities. AUS has three colleges, the College of Architecture, Art and Design (CAAD), the College of Arts and Science (CAS), The College of Engineering (CEN) and one School of Business Administration (SBA). CEN is the largest college with approximately 2,800 graduate and undergraduate students. AUS is an ABET accredited institution and as such all engineering students are required to take a discipline specific writing course entitled English for Engineers. This course is usually the fourth and final course in the series of required writing courses to meet the general education requirements to graduate from AUS and is taught by instructors in the Department of English. The writing courses are usually completed before the end of the second year of the four to five-year engineering degree program. After that, for most engineering students, they are not exposed to writing intensive assignments again until their final senior design projects. For some students at AUS this gap in their exposure to writing assignments has proven to be problematic when faced with the written component of their senior design projects. Although some departments in the College of Engineering have included required writing intensive assignments and undergraduate research projects in a few major courses to supplement the required general education writing course sequence this is not the case in the Department of Civil Engineering. At present, there are limited undergraduate research project expectations in any of the undergraduate courses. Thus, in order to help prepare his students to be more capable future engineers, the lead author introduced an optional research writing assignment to his students. This paper aims to provide readers with a rationale based on support from the literature and from the students involved in the research to introduce a writing intensive undergraduate research project early on in the engineering curriculum.

\section{Writing to Learn}

Numerous studies have shown that writing helps students learn in all disciplines as they go through the process of demonstrating their understanding of the material in their own words, often through a critical analysis of the content. As Fernandes [1] points out, 'the method of WTL is based on the idea that students can be given writing assignments, where, besides translating their thoughts into written language, they may discover new knowledge as well.' Although writing intensive assignments, with a focus on writing to learn (WTL) have long been the domain of humanities and arts courses, all students can benefit from writing intensive assignments $[2,3]$. There are two types of WTL assignments that are reported to be effective to help students in STEM disciplines: "1) Assignments that focus critical reflection on one's epistemic beliefs regarding knowledge and understanding, problem solving, and application of knowledge and 2) assignments that engage the student in formulating a reasoned argument' [4]. 
In order for a WTL program to be successful, Manuel-Dupont [2] suggests that professors and program developers must understand and adhere to the beliefs that, one, writing skills must be practiced and reinforced throughout the curriculum; two, learning occurs in the writing process and three, written discourse is central to a university education. As she states, 'unused skills will atrophy, no matter how well they were taught in the beginning. Formal and informal writing assignments can help students make links, catalog information, and compare and contrast ideas to better understand technical concepts. It is the responsibility of all educators to ensure that students have experience with the styles of writing most used in their academic disciplines' [2].

\subsection{Writing intensive assignments in STEM}

Incorporating writing assignments in discipline specific courses, especially in STEM is an important aspect for student success [5]. For engineering students in particular, including writing assignments into the coursework helps the students develop writing skills they will need later in their professional practice $[6,7,8]$. According to Wheeler and McDonald [9], 'writing helps the individual writer to think critically and has long been recognized as a vital component of engineering education'. However, in spite of the inclusion of communication skills, including written communication, within the ABET accrediting standards and the belief by many Engineers that written communication is a valuable skill, many engineering programs around the world do not incorporate writing intensive assignments in the majority of their required undergraduate engineering courses [10].

In addition to preparing students for senior projects or masters' level writing expectations there are other reasons to focus on writing within engineering students' discipline specific courses. Sharp, et al. [11] found that 'Engineering educators are concerned with students" tendencies towards "shallow learning" exemplified by a focus on memorizing only those essentials needed to pass the next examination'. To help engineering students move away from shallow learning to deep learning, writing intensive assignments may help.

However, 'despite substantial evidence that writing can be an effective tool in student learning and engagement and that WTL strategies can enhance knowledge acquisition and cognitive skill development in science disciplines WTL practices are still not widely implemented' [4]. Some reasons for this may have to do with engineering faculty and students' views of writing. Over-worked engineering faculty may be concerned by the extra time required to teach and grade writing intensive assignments [2]. In addition, some students do not see the value in writing assignments [6]. For example, the students involved in Plumb and Scott's 2002 research could not see the link between the required writing courses they had to take and the writing they did for their engineering courses. The students acknowledged that the skills they learned in their technical writing courses were valuable but noted that these skills were not always reinforced in writing assignments in their technical courses. In order for a writing intensive assignments to be successful, faculty need to see the value of writing as an engineer and convey this idea to their students [2].

\subsection{STEM Undergraduate Research Projects}

Seymour, et al. [12] in their extensive review of the literature found numerous studies outlining the following benefits to students who participate in undergraduate research projects in STEM:

- Increased student interest in the discipline

- Enhanced career preparation: greater readiness for more demanding research and for professional careers in the sciences

- Clarification, confirmation, interest in, or choice of, a career path (including graduate school)

- Increased skills in research and lab techniques, communication (writing, presentation, and argument)

- Gains in: critical thinking and understanding how to approach research problems

- Increased understanding of the research process

- Increased self-confidence in ability to do research

- Improved approach to learning: shift from passive to active learning

- Becoming part of a learning community and bonding with faculty.

In a study done specifically with 418 alumni, 59\% of which were Engineering or Science graduates, to assess their perceptions of the usefulness of their involvement in undergraduate research projects, the respondents reported that they benefited positively from their involvement in undergraduate research, through improved skills and abilities related to writing and conducting research. $80 \%$ of the respondents reported that they had pursued graduate degrees, with $67 \%$ carrying on to the $\mathrm{PhD}$ level. These respondents noted that their involvement in undergraduate research projects had helped prepare them for graduate studies [13].

As the evidence from the literature suggests, incorporating undergraduate research and writing intensive assignments in major courses has many benefits for engineering students. For example, these assignments provide an opportunity to the 
undergraduate students to explore and gain the skills needed for future jobs or higher education at the Master's and Ph.D. levels. In addition, it ensures continuous development of the undergraduate education, offers state-of-the art knowledge at an early stage and emphasizes the importance of lifelong learning.

In this paper, we discuss an optional course-related research writing assignment, and the students' perceptions of its value to their learning in an undergraduate civil engineering course.

\section{The Study}

The study was guided by the following question:

What benefits, if any, did the students gain from their participation in an optional research project in their undergraduate Civil Engineering course?

\subsection{Participants}

57 students enrolled in an undergraduate course in Civil Engineering at AUS over a course of six semesters were involved in the research. The percentage of males and females is shown in Table 1. The students represented more than 10 different nationalities including American, Canadian, Egyptian Emirati, Indian, Jordanian, Lebanese, Omani Palestinian and Saudi. Students' participation in the project and the data collection for this research paper was all voluntary and they were allowed to drop out of either at any time.

Table 1. Percentage of male and female participants over six semesters

\begin{tabular}{|l|l|l|l|l|l|l|}
\hline Semester & 1 & 2 & 3 & 4 & 5 & 6 \\
\hline Male & 61.5 & 60.5 & 60 & 75 & 60 & 50 \\
\hline Female & 38.5 & 39.5 & 40 & 25 & 40 & 50 \\
\hline
\end{tabular}

\subsection{Description of the Optional Assignment}

The course, CVE 224 is a required course for all declared Civil Engineering majors at AUS. It examines properties of construction materials (aggregate, Portland cement, admixtures, concrete and bituminous materials used in construction and maintenance of structures, roads and pavements); design of concrete mixes including admixtures; concrete trial mixes on construction site; concrete curing methods; concrete strength and durability; design of paving mixtures; and production, specifications, tests and quality control of various construction material.

The research component consisted of three main parts, an orientation/introduction session, a library session, and weekly meetings to discuss progress.
Students were divided into groups of three to four students each. Research topics were assigned by the professor. A five-page conference format paper was required per group at the end of the semester.

The optional group research writing assignment was listed on the syllabus. The Professor outlined this optional assignment, along with the required course assignments in the first week of classes. Students who expressed interest in the assignment were asked to attend an information research orientation session. As noted by Plumb and Scott [3] in their research with undergraduates into the introduction of research assignments in engineering classes, 'one notable but not surprising discovery during this process is that students produce better writing when they are responding to a sound writing assignment. The better writing assignments challenged students to research their topics and to provide evidence of that research. These model assignments also gave students clear instructions, described the audience for the assignment, and specified how the assignment would be evaluated' In the orientation session the professor gave a short presentation on the project which included important things to remember, a list of possible research topics and research methodology. The research assignment followed a process writing approach and students were given advice and guidance on their research projects throughout the course of the semester during the weekly progress meetings. One of the purposes of the assignment was to allow students the opportunity to engage in the research process and learn from it thus taking a traditional grade based approach to evaluation was not appropriate. Students were given extra credit based on their participation in the process rather than a grade on the final product. Students were expected to commit to completing the assignment, especially after the groups were formed, however, they were given the option to withdraw before the end of week 5 in the semester.

In addition to the orientation session led by the Professor, the students met with the engineering liaison librarian for a more detailed explanation of the research resources and help available through the AUS library. In this session, the librarians gave more information on the engineering specific data bases, some tips on narrowing a search using appropriate keywords and the importance of correct citations to avoid any unintentional plagiarism.

\subsection{Data Collection}

Two data sets were collected. The first data set is from students who participated in the optional research projects in the semester in which they were enrolled. The students were surveyed before their participation and then again after they completed the research project. Permission to survey the students for research purposes was granted by the AUS Internal 
Review Board. Both surveys were anonymous and voluntary. The first survey focused on the students' motive for participating in the optional assignment and their previous research involvement and expectations of the current group research project. The second survey focused on the students' experience throughout the optional research project.

The second data set is from AUS alumni who participated in the research. These students were contacted via the Alumni office and asked to reflect on the impact their involvement in the optional research project has had on their academic and professional lives.

\section{Analysis}

The purpose of the short survey given before the research began was to get to know the students better and to determine how much help they might need during the project. They were asked specifically about their motive for participating in the optional research project, whether or not they had worked on a research team before and if they were aware of the expectations and limitations of the research. Students were also asked on how they perceived their current research skills in terms of methods and resources and their knowledge of the research topic.

The students were given a list of options to choose from that described their main motive for participating. Students may have participated for more than one reason, however, the question allowed for only one answer. For $42 \%$ of the students' the main motive for participating in the research project was to learn more about the subject. $19 \%$ of the students participated to get extra credit. Other reasons given included having the opportunity to work closely with the professor, and a chance and to gain familiarity with the research process which will be useful in their future occupations and further education.

When asked to rank their level of comfort and knowledge of the research process, the majority of the students noted that they felt confident in their research skills. Their confidence could be due to their experience from the required general education writing courses taken at AUS prior to their enrollment in CVE 221. Students were least confident on the research topic, where the topic was unfamiliar to $44 \%$ of students. Out of 57 students who completed the survey, 32 students had never been part of a research group before while 47 students were aware of the expectations and limitations of the activity. This was important information to help guide the activities to support the students through the research process.

The purpose of the survey conducted after the research was to better understand the students' perceptions of the optional research project. The students were asked about the preparation/ information sessions, the research progress meetings and their overall research experience.

\subsection{Preparation Sessions}

$67 \%$ of students noted that they found the research orientation session to be very useful. They also made a number of suggestions to improve the sessions. These included having several shorter sessions instead of one long one. In these extra shorter sessions, the students suggested having research samples available and giving the students the opportunity to show their research work. They also noted that adding a session for the layout of the paper and having a session for APA referencing and report writing. These suggestions speak to the issue of students transferring their writing skills from the required writing courses to writing to learn within their discipline. As noted in the literature, it can be difficult for students to make these connections.

$33 \%$ of the students said they found the library information session useful. However, the majority of the students did not follow up after the library session and ask the library staff for help. Those who asked for help were divided equally into those who found the staff helpful and not helpful.

\subsection{Weekly Research Meetings}

$82 \%$ of students also found the progress meetings were helpful to them and their group. Those who were neutral about the meetings commented that members would only meet to distribute work, that they came unprepared to meetings or that they worked on their own, thus making meetings redundant. Students also praised the meetings with the professor, stating that those were more helpful and that they were disappointed when they were unable to have guidance or were unable to meet him.

\subsection{Overall Research Experience}

Students were also asked what they liked and disliked about the experience as well as any suggestions to improve the project for the future. A majority of students liked the knowledge that they gained as well as working in teams while the majority disliked the limitations on length of the paper and some felt they did not have enough time. The top suggestions were to offer more time to complete the project, to be able to conduct primary research, to offer more extra credit and to be allowed to choose teammates.

The students also responded to their experience with their group mates. The students' answers to the open-ended question, 'Can you evaluate your experience with your group mates?' showed that the majority viewed their experience as 'good'. Others responded that they found the experience to be 
'interesting', 'beneficial', 'helpful' and some of their comments indicated they felt neutral towards their group mates and the group experience. Only a small number of students expressed that they found working in a group difficult. The reasons for the difficulties had to do with uneven contributions to the project, or group mates not adhering to deadlines. However, one student was able to view the difficulties as a learning opportunity. As he/she wrote, "The major fault we had was that our work was not organized as it must be. This will help to avoid such a problem in any future projects!"

The purpose of the research project was not only to teach the students research skills but to increase their knowledge of the topic as well. The topics related to civil engineering were assigned by the Professor. 92\% of the students responded that they were unaware of the topic. When evaluating their knowledge after the project was complete, $70 \%$ responded that their knowledge was enhanced while others mentioned that they were now familiar with the topic and felt they had a better understanding of it.

In addition to gaining a better understanding and familiarity of the topic, some of the students' comments centered on the impact of their new knowledge gained from the experience to their current and future situations as illustrated in the following comments from three of the students:

I know more about the subject and I feel that it will help me in the future.

I know more about it and I know how to evaluate any material

My knowledge has certainly increased. About the topic, I know more. However, the best thing is that the concept of civil engineering being simple and old fashioned has been eliminated from my mind. It certainly is as new as any other field.

Overall, the students involved found the experience beneficial with some saying it was good or excellent and others expressing that it was interesting while others found the experience to be challenging or time consuming.

As noted by Madan and Teitge [14], 'there are numerous benefits for undergraduate students who get involved in research. Research experience allows undergraduate students to better understand published works, learn to balance collaborative and individual work, determine an area of interest, and jump start their careers as researchers'. When asked to evaluate their overall experience with the research option, several students echoed these observations. For example:

Enjoyable, challenging, group working experience.
Overall provides us with basic knowledge about how to write a paper.

From the research now I know more about the topics, more about the current international and local market for our topic.

It provided me with an outlook at how the masters [degree research] or any research will be.

\subsection{Closing the loop}

To close the loop and see if there was any lasting benefit from the students' participation in the optional research project, the same students were contacted by email. A link to the online survey was sent to the alumni via AUS's Office of Alumni Affairs.

10 students responded. All of the respondents had graduated with a major in civil engineering from AUS within the last five years. Five of the respondents have Bachelor Degrees and five have continued on to achieve their Masters' degrees. All 10 recommended that future students should participate in the optional research project. One student commented, 'Yes definitely, it's a learning opportunity that shouldn't be missed'. Two students noted that, in their opinions, the research project should become a mandatory component. As one student said, 'I recommend it becomes mandatory since it helps the student understand more about the material by reading different papers. Also, it helps when they do the Senior Design'.

The students were asked to consider what benefits, if any, they gained from participating in the optional research project. Nine out of the ten former students responded to this question. Although one student noted that he/she benefitted from the extra grade gained from his/her participation in the project, he/she also noted, like many other students that he/she learned how to write a research paper properly and learned more about the topic. Another student commented that he/she "was able to gain some insight into the practical applications of what we were being taught. It wasn't just numbers and laws anymore'.

The two students' comments below speak to the longer-term impact of their involvement in the optional research project:

It was a very good introduction to civil engineering academic research. Because of it I decided to start my 2 years work as a research assistant in the civil engineering department.

The professor gave us very useful guidance on how to produce a preliminary research paper with all the lab testing methods taught inside the classroom and lab. 
Because I took part in that research in my 1st job, I was in charge of the concrete testing and reporting in my 1 st month as a construction engineer, as I had a very good background on the matter. I'm very satisfied with the knowledge I gained doing the research. Thank you!

In addition to the ten students who participated in the survey, further investigation revealed that out of the original 57 students who participated in the optional research project, to date, $44 \%$ of them have continued on with their studies and have earned their Masters' degrees in Engineering. We cannot say that the research project itself is the reason these students have continued on with their studies. However, data from the survey given to the students after their participation in the optional project, indicates that for some, the students were interested in graduate studies. The students were given a choice of three options, plus an "other" open-ended option on the survey and asked to choose the one that best described their reasons for participating. As shown in Figure 1, the main motive for the students' participation in the optional research project was to learn more about the subject. This was followed by getting extra credit and getting to know the professor better. In the "other" category, students wrote in that they participated to gain familiarity with the research process to help them in their future careers and to prepare them for Master's studies.

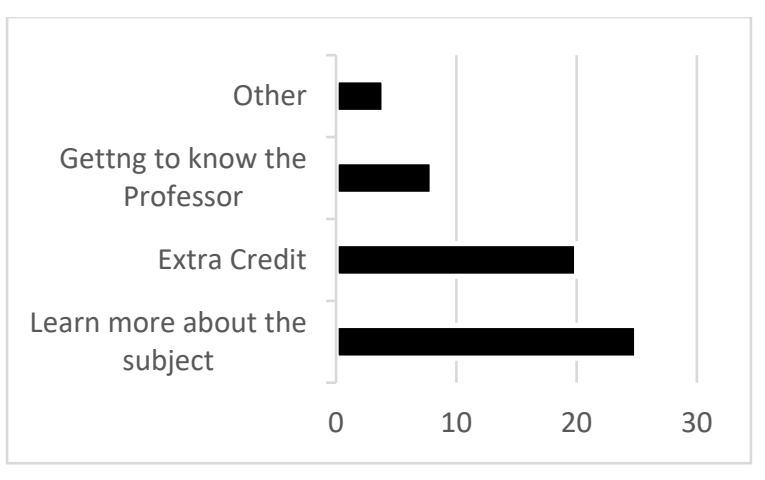

Figure 1. Reasons for Participating in the Optional Research Project $(n=57)$

\section{Conclusion}

Voluntary participation in a project such as an optional research project is a big commitment for undergraduate students. The students who chose to participate in the optional group research project outlined in this paper did so because they could see the value of participating to their overall educational experience. As they noted, they learned valuable research skills, how to produce a conference paper, how to work effectively in groups and a deeper understanding of the topic. For some, they also participated to receive the extra credit grade assigned to the project.

As shown in the literature, well-structured writing assignments can lead to enhanced learning. Other benefits include a deeper interest in the topic stemming from a greater understanding achieved through the writing process. This in turn could lead to a commitment to life-long learning. However, in spite of this, most engineering courses do not have a writing intensive assignment as part of their assessments. Based on the feedback from the students and their perceptions of the usefulness of the optional research writing assignment, it is highly recommended that a variety of writing intensive assignments are incorporated into the undergraduate engineering curriculum in all departments as early as first year.

A focus on writing to learn requires a commitment from professors and many engineering professors may not feel that they have the enough training to do so $[15,16]$. However, in order to incorporate a writing to learn approach professors do not need to start with something as large as a research project. There are numerous other activities that will achieve the goal of helping the students learn through writing. For example, low stakes reflective activities such as:

- Think-Write-Pair-Share: Ask a question and prompt students to think about their answer individually for a minute and write down their response. Students then pair up and discuss their responses with a partner.

- One-minute paper: Give students a topic to write about. First, ask them to think about the topic without writing anything for one or two minutes and then give them one minute to write as much as they can about the topic.

- Email the author: In small groups, ask the students to write an email to the author of an article or textbook. They can ask the author a question they have about the content or write their responses to the material in the article. After reviewing the email, have students send the email.

- Microtheme: A microtheme is a mini-essay written in-class on a focused topic from class. This activity can be done in groups, pairs or individually. The professor sets the topic and gives the students five to ten minutes to write.

- Write an exam question: Have students prepare exam questions that could be used in

- $\quad$ quizzes, midterms, and finals.

- Logbooks: Ask the students to complete frequent short entries either online or in an actual notebook summarizing and assessing material or connect course topics with their own observations. 
In today's ever changing world, to become a successful engineers our students must be able to offer innovative solutions to real-world problems, both in the classroom and in their future jobs [7, 16]. Thus, we must help provide them with opportunities to move beyond memorization and recognize that critical thinking is an essential skill for engineering students. As this research has demonstrated, incorporating writing to learn activities, no matter how large or how small is an effective pedagogic tool to help develop these much needed skills.

\section{References}

[1] Fernandes, A. S. "Writing to learn writing skills - a case study". European Journal of Engineering Education, 37, 2. 2012. pp. 179-192. doi:10.1080/03043797.2012.672964.

[2] Manuel-Dupont, S. "Writing-Across-the-Curriculum in an Engineering Program". Journal of Engineering Education 84. 1996. pp. 35-40.

[3] Plumb, C. and Scott. C. "University of Washington Outcomes Assessment of Engineering Writing at the University of Washington". Journal of Engineering Education 91. 2002. pp. 333-338.

[4] Reynolds, J. A., Thaiss, C., Katkin, W. and T. J. Thompson. 2012. "Writing-to-Learn in Undergraduate Science Education: A Community-Based, Conceptually Driven Approach". Life Sciences Education, 11. pp. 17-25.

[5] Boyd, G. and M. F. Hassett. "Developing Critical Writing Skills in Engineering and Technology Students". Journal of Engineering Education 89. 2000. pp. 409-412.

[6] Hanson, J. H, and Williams, J. M. "Using Writing Assignments to Improve Self-Assessment and Communication in an Engineering Statics Course". Journal of Engineering Education, 97. 2008. pp. 515-529.

[7] Gimenez, J., and J. Thondhlana. "Collaborative writing in engineering: Perspectives from research and implications for undergraduate education". European Journal of Engineering Education, 37, 5. 2012. pp.: 471-487. doi:10.1080/03043797.2012.714356

[8] Gunn, C. and Raven, J. "Evaluating teacher feedback in writing classes." Academic Exchange Quarterly 9, 2. 2005. pp. 265-270.

[9] Wheeler, E. and McDonald, R. L. "Writing in engineering courses". Journal of Engineering Education, 89, 4. 2000. pp. 481-486.

[10] Yalvac, B., Smith, H. D., Troy, J. B., and P. Hirsch. "Promoting Advanced Writing Skills in an Upper-Level Engineering Class". Journal of Engineering Education, 96. 2007. pp. 117-128.

[11] Sharp, J., Olds, B., Miller, R. and Dyrud, M. "Four Effective Writing Strategies for Engineering Classes". Journal of Engineering Education 87. 1999. Pp. 53-57.
[12] Seymour, E., Hunter, A., Laursen, S. L. and T. Deantoni. "Establishing the Benefits of Research Experiences for Undergraduates in the Sciences: First Findings from a Three-Year Study". 88. Science Education. 2004. pp. 493-534.

[13] Bauer, K, W. and J. S. Bennett. "Alumni Perceptions Used to Assess Undergraduate Research Experience". The Journal of Higher Education, 74. 2003. pp. 210-230.

[14] Madan, C. R., and B. D. Teitge. "The Benefits of Undergraduate Research: The Student's Perspective". The Mentor: An Academic Advising Journal. 2013. Retrieved from http://dus.psu.edu/mentor/.

[15] Gavin, K. 2011. "Case study of a project-based learning course in civil engineering design". European Journal of Engineering Education, 36, 6. 2011. pp. 547-558. doi:10.1080/03043797.2011.624173.

[16] Yehia, S. and Gunn C. J. "Enriching the Learning Experience for Civil Engineering Students through LearnerCentered Teaching". Journal of Professional Issues in Engineering Education and Practice. 144, 4. 2018. pp. 1 6. 